\title{
Study on the Influence of Folk Fine Arts on Digital Media Art Teaching at Colleges and Universities in Multiple Perspectives
}

\author{
Hui Li \\ School of Art and Design \\ Huanghe Science and Technology College \\ Zhengzhou, China \\ e-mail: 46119080@qq.com
}

\begin{abstract}
A folk fine art is a treasure of traditional Chinese culture. Its unique form, content and style can have a great effect on the digital media art teaching, involving teaching objectives, teaching patterns, teaching contents and many other aspects. In view of this, this paper starts with the connotations and characteristics of folk fine arts and analyzes its influence in detail.
\end{abstract}

Keywords-folk fine arts; digital media art teaching; influence; research and analysis

\section{ABOUT FOLK FINE ARTS}

Chinese folk fine arts is a special category of fine arts, referring especially to a kind of fine art form which is produced mainly by ordinary laboring people from the lower class, based on their own living needs and developed continuously from collective inheritance and historical accumulation. It has dozens of forms, including painting, sculpture, toy, costume, drama, paper cutting, weaving and so on, and is characterized in a number of ways. Firstly, because China has a long history, vast territory and numerous ethnic groups, folk fine art is a collection and carries rich and diverse culture. Secondly, folk fine arts, created by the public of the Chinese nation, embody a unique cultural outlook and aesthetic standard. Thirdly, it is produced from productive labor and thus is extremely closely related to the life of working people. Finally, known as one of the parent arts of Chinese nation and evolving thousands of years, it is characterized by the continuity of traditional national culture. In contrast to the digital media art at colleges and universities, both of which are visual communication art, ancient folk fine arts is bound to inspire and benefit the young digital media art in many ways. An emphasis on, and the utilization of such influence, helps not only promote the teaching quality in essence and open a special path for the teaching of digital media art in China, but also provide a new mode of inheritance for folk fine arts, an ancient art, answering multiple purposes.

\section{CUltural Origin OF FolK Fine ARTS}

\section{A. Direct Inheritance of Folk Fine Arts from Primitive Art}

Just as cultural storage and the deposit of our country stems from primitive culture, so do folk fine arts. As can be seen from the study of archaeology, the primitive art created by our ancestors is primarily not aesthetic, but used for activities associated with primitive belief, including worship ceremony and witchcraft. A large number of ideas concerning deities are embodied in image symbols to express a variety of thoughts and ideas. Images become the visualized representation of ideas. Although folk fine arts has developed and changed greatly in terms of its specific content and form as time has passed, it still has an extremely close blood relationship with primitive art from all sides. From the aspects of its creation, motivation, aesthetic structure, theme and connotation, art form and so on, folk fine arts are still connected with the primitive art in pattern.

\section{B. Relationship between Folk Fine Arts and Folk Culture}

Folk culture is an inevitable topic when it comes to folk fine arts. If we take art as a magic mirror of life and believe that folk fine arts has the strength to positively reflect the social life, we can say that folk fine arts is not only a kind of folk culture, but an art form in which folk customs are truly and vividly described, showed and sustained. Its existence depends on all kinds of folk activities, to which it adds brilliant color. It is not only a folk fine arts starting with the occurrence and development of folk culture but a visualized carrier of folk culture. In folk fine arts, image symbols are not that simple themselves, but can go beyond the entities and the representation of life noumenon, and use a specific image and a combination of images to underlie a deeper level of meaning. For example, the "fish and lotus" pattern in paper cutting is nothing but a common portrayal of flowers, birds, fish and insects in the natural world on the surface, while intended to reveal the theme of multiplication of human in a deep sense. Image symbols of folk fine arts inherit folk culture. In folk fine arts, both the pictorial images and styles of tableware and vases are given cultural 
traits to embody the cultural characteristics of different regions, ethnic groups, folklore phenomena and stages of social development. From the perspective of cultural inheritance, a variety of folk fine arts works are the carrier for folk culture information. They are designed to be visual images, which contain a wealth of cultural information, so that people can understand the cultural connotation by decoding these visual images. These visualized and specific symbols, when handed down from generation to generation, also transmit the various folk cultures they carry to the general public, and in this way, folk culture can be inherited, developed and constantly strengthened in the process. For example, paper cutting, a form of manifesting folk fine arts, is generally rural womens' behavior for self-entertainment, as well as a native cultural phenomenon. In the process of teaching presentation skills and shaping features, these longstanding and profound traditional cultural connotations related to customs and seasons, life rituals and others of local life can be inherited concurrently.

\section{Folk Fine Arts for Utilitarian Use}

Folk fine art has a strong practicability and is primarily utilitarian rather than purely aesthetic. The practicability can be divided into two categories: one is spirit-oriented, like the lunar new year picture, window flower, festival lantern and so on which are intended to satisfy peoples' wishes for good luck and exorcism; the other is utility-oriented, such as jars, pots, bowls, dishes, bamboo weaving and other articles for daily use. Therefore, most of traditional forms of folk fine arts are embodied in the crafts that are always designed to serve a practical purpose and indispensable to life. However, for these articles for daily use, a variety of designs and patterns are typically employed to visualize the spiritual content of the first category, meanwhile, the style and craft of ware featuring cultural and aesthetic nature represent cultural characteristics in different nationalities, regions and social stages. Examples including different species of animals and plants are intertwined with humans in an organism to indicate peoples' wish for vitality; 福, 禄, 寿 (blessing, fortune and longevity), and other Chinese characters are combined with animals and plants to express the wish for happiness. In short, all categories and different art forms of folk fine arts illustrate profoundly peoples' desires and hopes for life without exception. The value of its pursuit of a spiritually utilitarian purpose has been greatly introduced to the folk aesthetic activities and affects the aesthetic judgments of the public. In the final analysis, folk fine arts are essentially utilitarian. The utilitarian tendency demonstrated by the folk aesthetic awareness is spiritual rather than super utilitarian. The understanding and feeling of beauty are unified with those of goodness. It is the utilitarian and practical aesthetic awareness that creates the rustic artistic images that feature high artistic value.

\section{ANALYSIS ON THE INFLUENCE OF FOLK FINE ARTS ON Digital MEDIA ART TEACHING}

\section{A. Innovation of Teaching Objective}

The goal precedes the action and plays a decisive role in the training orientation and quality of talent. Digital media art is a new multidisciplinary specialty integrating art with technology, and oriented to animation design, network multimedia design, digital film and television production and so on. Due to its distinctive technical features, its teaching objective is comparatively specific, which can be described as the skilled application of the acquired knowledge and skills for animation production, website design, multiple media and other practical work. The teaching objective is consistent with the actual characteristics of the specialty as it is, but it fails to advance with the times. In other words, teaching is disassociated with the market because the objective is too single-focused, making it difficult for students to meet the real needs of the market. The contemporary digital media art progresses with each passing day. The frequently updated production equipment and constantly changing target groups' aesthetic standard makes for higher demand on all practitioners. A solid grasp of knowledge and skills is the basic minimum, and creators are required to: attach equal importance on techniques and art, have a good sense of cooperation and innovation, and develop a distinct personality on creation. The integration of folk fine arts, the unique creation view, creation form, inheritance mode, ideological connotation of folk fine arts and the introduction of works of great success due to the application of folk fine arts have a positive effect on teaching content, teaching mode, teachers construction and other aspects. In this way, teaching quality can be effectively improved, and schools, teachers and students can better recognize their disadvantages and the difference between what reality requires of them and what education requires. They can then actively promote the transformation of teaching objective from simple to complex. As can be seen, folk fine arts is more like a catalyst which indicates, promotes and contributes to the above crucial transformation when teaching and training objectives deviate from the market demand.

\section{B. Enrichment of Teaching Content}

Digital media art design is a specialty emerging with social development and information technology innovation. With strong features of the times, its teaching content focuses on current fashionable knowledge and skills. Although such knowledge and skills are enough for general design, it is less effective at expanding students' aesthetic horizon, improving their ability for innovation and the formation of their personalities on creation. It is prone to developing students into a "product", produced in an assembly line. However, the integration of folk fine arts can greatly enrich teaching content and achieve the purpose of promoting students' comprehensive quality and ability. Examples include: Henan folk fine arts, which has a wealth of art types, such as New Year pictures, wheat stalk pictures, clay dogs, shadow puppets, paper cutting, etc. In the styling, it not only truly represents the objective things, but also 
features bold imagination and employs a reasonable approach for processing, refining and recreation. For example, bold and unconstrained woodblock New Year pictures, vivid clay dogs and others stem from the wisdom of working people and embody their unique view of style, in may respects inspiring the animation modeling. In color application, folk fine arts typically employs the traditional five colors including red, yellow, blue, white and black, and applies them boldly and specifically. Although its color assortment is relatively simple, its color impact is strong. Examples include: Zhuxianzhen New Year woodblock paintings, which effectively illustrate a strong festive atmosphere with their rough figure style and the application of supplementary bright colors in a large area. As for the aesthetic standard, folk fine arts is born from the labor, so it is unconstrained by any value and utilitarian thinking and reflects the most essential taste and aesthetic appreciation as well as the unique folk customs and humanistic connotation in the Central Plains. It can be seen that the styles, colors and ideas of folk fine arts extend current teaching content, and only through learning and using this content as a reference, can works exhibit the most valuable national style.

\section{Extension of Teaching Mode}

The traditional digital media art education mostly employs the teaching-based method where teachers explain the knowledge and skills while students are instructed to practice and create. The above teaching mode is more suitable for general cultural studies rather than digital media art teaching. As for the artistic creation featuring creativity and practicality itself, although the existing teaching mode guarantees on-track, orderly teaching, it also plays a negatively constrained role, while the introduction of folk fine arts can naturally promote the transformation of teaching methods for better teaching results. A variety of specific modes are available. For example with animation design, we can set a topic integrating folk fine arts and animation design for the creation of animation works with local style. In the specific implementation process, we can work in groups where teachers designate the responsibility. These responsible persons divide work among their members, including object selection and information collection, specific creation, office support and so on. We can invite some front-line designers to evaluate the works upon completed and give physical rewards and mental encouragement. In this way, the students' enthusiasm and initiative can be enhanced and their practical ability and cooperative ability can be effectively trained. Another example is the active cooperation with local government departments. We can publicize the local folk fine arts by using animation, website and media design, and other formats to sign a long-term cooperation agreement for economic returns. It is also advisable for us to take students to the birthplace of certain folk fine arts for field investigation and collection for the purpose of the materials accumulation for creation. The introduction of various forms can greatly change the traditional teaching mode and make it more suitable for the teaching purpose, which is extremely critical for the promotion of teaching quality and students' personal development.

\section{Promotion of Teacher Capacity Construction}

In recent years, the Ministry of Education of PRC has strongly advocated the "double-qualified" teacher capacity construction where teachers are required to hold not only teacher qualification but also professional experience. The above teacher capacity construction works well within the specialty of digital media art. As can be seen from the current situation, a majority of teachers have received professional training and reach a high level of theory, but they are generally lacking practical ability. In other words, they are inexperienced in creation and have produced a small number of works, which is obviously undesirable for teaching practice and makes it impossible to set an example and make a demonstration for students. The integration with folk fine arts is an effective way to channel and promote teachers' practical skills. On the one hand, folk fine arts is characterized by a wealth of forms and every region has its typical style, facilitating teachers' investigation and application; on the other hand, the creation of works featuring national style plays an exemplary and leading role and leads students to recognize the value and significance therein. Specifically, teachers can carry out systematic and in-depth research on a certain kind of folk fine arts by virtue of project application, establishment of studio, etc. Based on this, they are expected to conduct an investigation of the related industries, and do their internships to get first-hand information, accumulate sufficient materials for creation and then to produce specific works. If conditions permit, these works can be developed into a series or a brand to play a greater value and significance. A successful illustration can be found from this point. In the middle of the last century, the tile of "China Style" was popular in the Chinese animation cycle. Some creators who integrated folk fine arts in their works won widespread praise and recognition for their distinct national style. Examples include: "Real and Fake Li Kui" and "A Daoist from Lao Mountain" using the styles of traditional wooden, clay toys as a reference, "The Monkey King" and "Carp Jumps over the Dragon Gate" using styles and colors of New Year pictures - making the world-renowned Chinese animation. Since students have limited abilities, teachers are the best candidates to carry forward folk fine arts. Teachers are supposed to emphasize the integration of folk fine arts in their practical and creative work, which not only meets the needs of teaching itself but also represents the national responsibility of art design teachers.

\section{CONCLUSION}

In summary, in recent years, China's digital media art has also ushered a great development in the context of globalization, generating an increasing demand for a quantity of high quality talents. Specific to teaching, a key factor in promoting teaching quality in essence is the emphasis on and application of folk fine arts. By doing this, students can master the knowledge and skills, develop the national awareness, which is most precious in artistic creation, and folk fine arts can obtain a new channel for inheritance. If all the students are very familiar with folk fine arts and adept at using it, Chinese digital media art 
design will show a distinctive national style; and become world-renowned in the international arena for this unique feature.

\section{REFERENCES}

[1] Jiang Dengpan. A Brief Analysis on the Inheritance and Innovation of Traditional Folk Fine Arts in China Modern Design [J]. Art Education. $2011(04)$

[2] Li Xiaoling. Construction and Practice of Professional Practice Teaching System of Digital Media Technology [J]. Chinese Vocational and Technical Education. 2011 (17)

[3] Li Sida. Exploration of Teaching Mode of Digital Media Art [J]. Journal of Beijing University of Posts and Telecommunications (Social Sciences) 2010 (04)

[4] Xing Hongliang. Characteristics of Digital Media Art Design and its Influence on Traditional Art Design [J]. Art and Design (Theory). $2011(03)$ 